\title{
Geographical Reconnaissance of Household in Northern Nigeria towards Optimizing Indoor Residual Spraying Method for Malaria Elimination
}

\author{
Williams 0joํㅜ, Moses Onazi ${ }^{2}$, Olakunle Olaniyi ${ }^{3}$ \\ ${ }^{1}$ Department of Geography and Ecosystem Analysis, Lund University, Lund, Sweden \\ ${ }^{2}$ Research and Data Solutions, Abuja, Nigeria \\ ${ }^{3}$ Stuttgart University, Stuttgart, Germany \\ Email: izehieghogho@gmail.com
}

How to cite this paper: Ojo, W., Onazi, M. and Olaniyi, O. (2016) Geographical Reconnaissance of Household in Northern Nigeria towards Optimizing Indoor Residual Spraying Method for Malaria Elimination. Journal of Geographic Information System, 8, 737-748.

http://dx.doi.org/10.4236/igis.2016.86057

Received: September 5, 2016

Accepted: December 27, 2016

Published: December 30, 2016

Copyright $\odot 2016$ by authors and Scientific Research Publishing Inc. This work is licensed under the Creative Commons Attribution International License (CC BY 4.0).

http://creativecommons.org/licenses/by/4.0/

\begin{abstract}
As a part of an effort to roll back malaria in Nigeria, exploring the use of geographically related tools triggered the use of modern approaches of knowing the spatial distribution of target populations to attain significant malaria elimination intervention. GIS tool was used for geographical reconnaissance (GR), providing demographic data on respondents' household and spatial information on the distribution of households in the selected location. A cross-sectional study design was used to collect spatial data in the two locations, while a quantitative questionnaire was used to collect the household data. The analysis of field data indicated that 49,500 unique households were enumerated and thus included in the Indoor Residual Spraying to prevent malaria infection, covering 424 towns in the two Local Government Areas (LGAs). 383,301 persons were recorded during the GR exercise in Doma and Nassarawa Eggon LGAs out of which 79,339 were children of agesless than five years, with 13,526 pregnant women. Further data analysis revealed that the average number of persons per household in both LGAs was approximately eight. The spatial information from the GR provides a foundation for an updateable database for any future survey for developmental activities in Nigeria. The use of modern GR approach has proved to be accurate, reliable and more cost effective and less cumbersome than the traditional approach in the collection and geo-positioning of household data. Use of Garmin e-Trex GPS handheld instruments to collect household data in the designated areas removed the constraints of expensive Personal Digital Assistants and reduced errors of wrong location coordinates. Several African countries which did not use GR or applied the use of Geospatial tool appropriately had setbacks. The previous study in other countries showed limitations which was characterized by substantial inherent logistical and technical challenges culminating in missed targets. This setback was
\end{abstract}


addressed in our study.

\section{Keywords}

Geographical Reconnaissance, Geographic Information System, Global Positioning

Systems, Indoor Residual Spraying, Local Government Area

\section{Introduction}

Over 40 percent of the world's population lives where there is a risk of malaria. The disease causes widespread premature death and suffering, imposing financial hardship on poor households, and holds back economic growth and improvements in living standards [1]. The depth of this endemic disease was shown in a global study of malaria, highlighting opportunistic areas for malaria elimination and intensified malaria control [2].

As a part of this increased focus, current strategies for the reduction of the global burden of malaria and the eventual elimination of the disease have been outlined in the Roll Back Malaria (RBM) Global Malaria Action Plan (GMAP). With recent global attention, most member states under the United Nations umbrella have made a commitment to roll back malaria towards achieving Sustainable Development Goal (SDG) 2030, so there is a refocus of intensive malaria control on the world agenda [3].

In Nigeria, Malaria is still one of the major causes of overall mortality in Nigeria. The ministry of health data continues to report that half of all hospital patients' cases of treatment are malaria infections. The disease is responsible for 25 percent of the nation's infant mortality, 30 percent of childhood mortality and 11 percent of maternal deaths. Nigeria contributes to 23 percent of the world's malaria cases, and 97 percent of the population is at risk.

For many years, the country had focused on treatment approach, until recently, more strategy is now on prevention methods, of which indoor residual spraying (IRS) is one. The public body responsible is the National Malaria Elimination Program of Nigeria, which was tested in Northern Nigeria in 2012 [4].

Measuring geo-locations and route planning for a precise target of the population affected, Geographical Reconnaissance (GR) is an imperative tool for use.

GR is a planning tool that combines household census and spatial mapping to determine the density, population size, location and accessibility of settlements within target areas.

Geographical reconnaissance (GR) as a planning tool involves a household census and mapping to determine the number, location, and accessibility of settlements within target areas. This facilitates research objectives as it is generally being used to collect geographic information system (GIS) and population data useful for strategic local level planning.

Our study used new technology to realize the GR processes, an approach that is bet- 
ter than the most commonly used traditional GR operations.

This study used modern GR approach, using Global Positioning Systems (GPS) [5] [6] to collect geographic information system (GIS) and population data useful for precise strategic local level planning and implementation.

\section{Materials and Method}

Below is a detailed explanatory diagram showing logical steps designed and followed through to complete all the research processes undertaken in this study, from problem identification to results and conclusion (Figure 1).

\subsection{Study Location}

Under the United States President's Malaria Initiative (PMI) the Africa Indoor Residual Spray (AIRS) project managed by Abt Associates was tasked to establish an Indoor Residual Spray (IRS) operation in Doma and Nassarawa Eggon local government areas (LGAs) of Nassarawa State, Nigeria. The State is situated in the North Central geo-political zone of Nigeria and was established on October 1, 1996 from Plateau State [7] (see Figure 2).

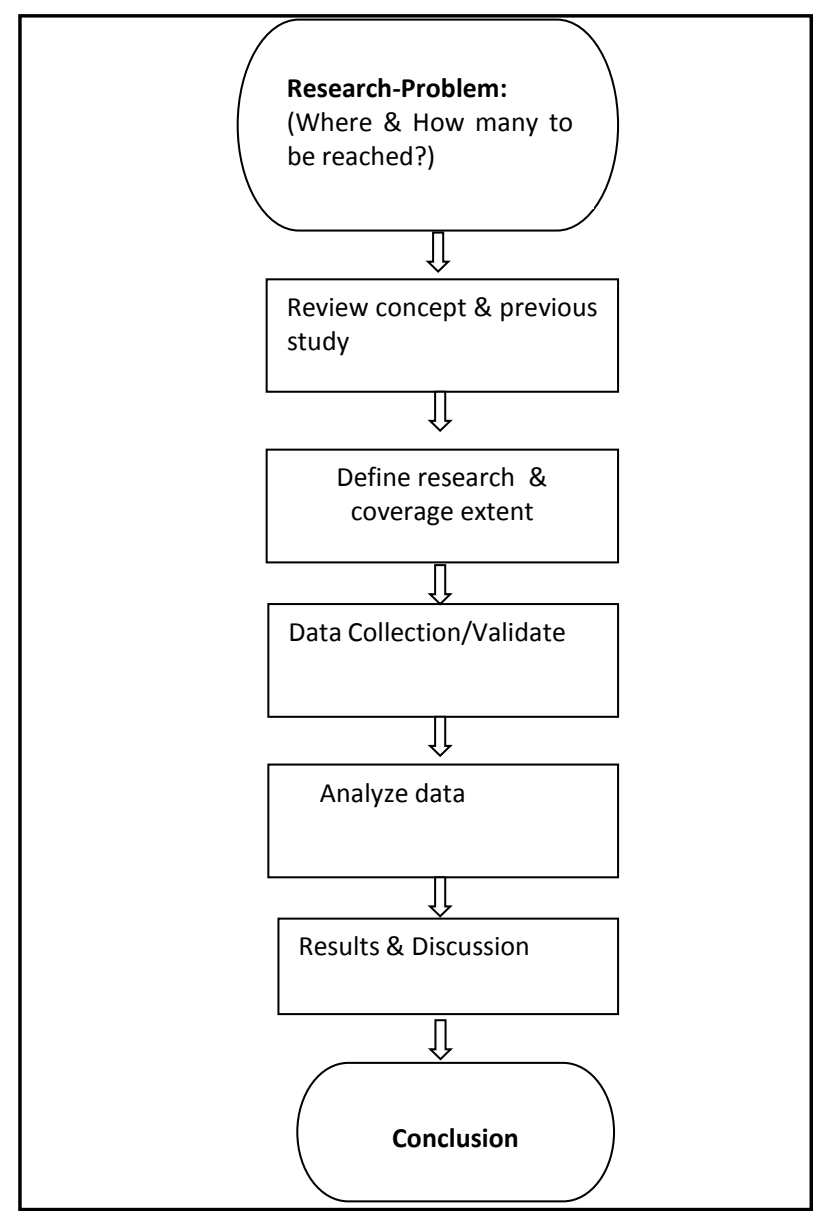

Figure 1. Diagram and flow chart of research methodology. 


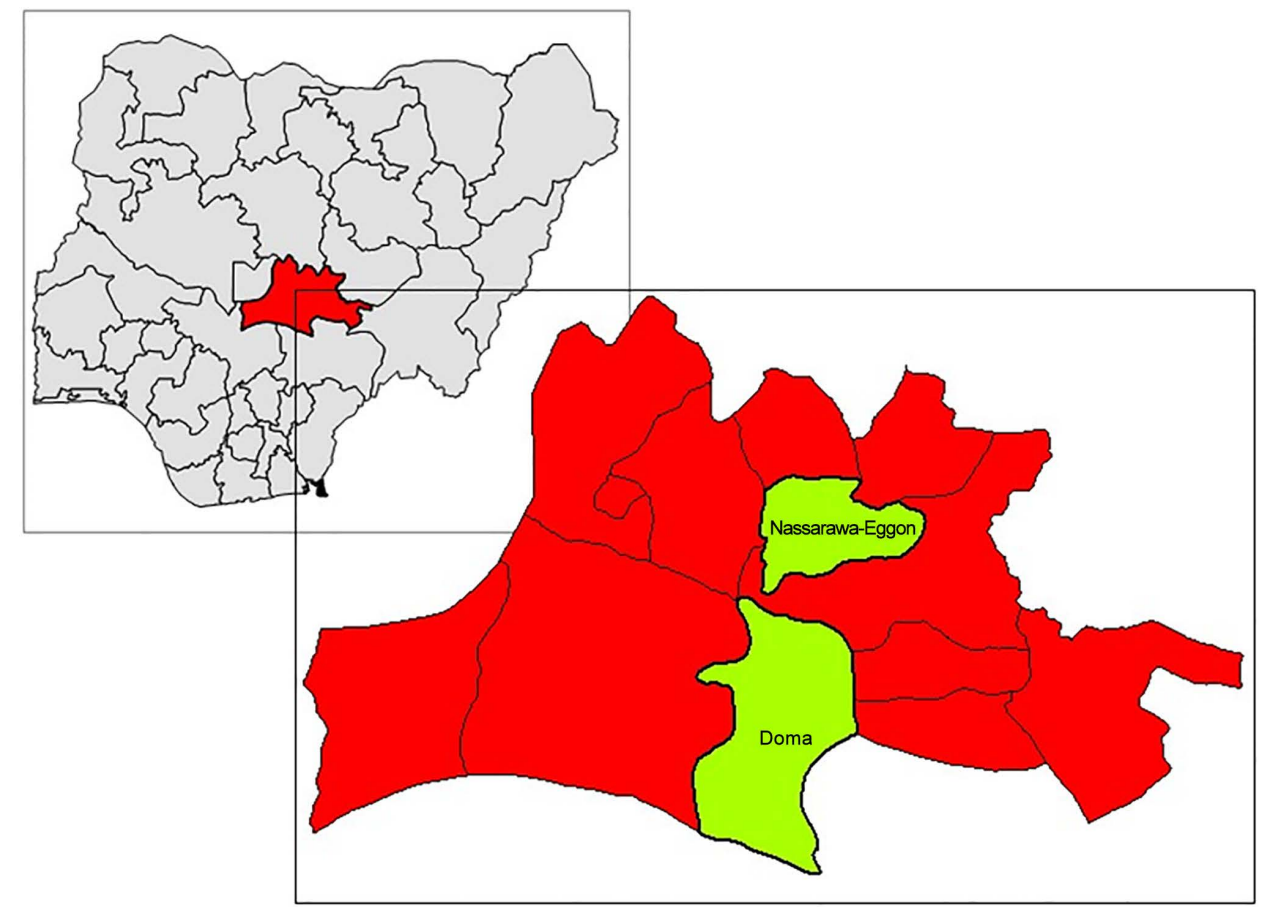

Figure 2. Map of Nigeria showing Nassarawa State and the selected LGAs for IRS.

Nasarawa State was estimated to have a population of about 1.86 million people with about 30 different ethnic groups of distinct cultural heritage' in the 2006 population census [8] [9]. With a growth rate of $2.9 \%$ the current population of the State was projected to be 2.22 million people in 2015 .

\subsection{Desk review}

Despite the use GR and other control tools to eliminate malaria, the study still showed that Malaria control action plans are dying out due to improper implementation, inadequate surveillance and lack of geo-referenced information to pinpoint the trouble spots for timely preventive actions [10].

A previous research study in the work of Kelly (2010), demonstrated the use Geographical Reconnaissance in the elimination provinces of Temotu, Solomon Islands, and that eventually provided as trategy for spatial distribution of target populations to support contemporary malaria elimination interventions. He used modern techniques to ensure effective and efficient operational tool via geospatial analysis, now guiding them in scaling-up of priority interventions [11].

Gerald also demonstrated in his thesis work, how the GR mapping and data collection; frontline vector control and malaria prevention intervention management using high resolution geospatial surveillance — can rapidly aid rapid reporting and mapping of confirmed cases by household in 2013 [12].

Since Zambia re-introduced the IRS program to control malaria in 2002, the country has developed standard guidelines, which has helped one of the main interventions executed in partnership with private sector. The guidelines, however, contributed to the 
development of a user standard operation procedures used which was used in the Nigerian study [6].

\subsection{Methodology}

The household was used as the primary sampling unit for the GR operation [13]. It is important to note that households in both LGAs lived in multiple, separate or shared single buildings which might consist of sleeping areas, kitchens, corridors, storage areas and animal sheds or compounds with stand-alone structures for sleeping areas, kitchens, storage areas and animal sheds.

Followed by data collection tools that captured GPS coordinates, household identification (IRS card number), village/town name/ward, name of head of household, number of individuals residing in each household, number of children less than five years of age in the household, number of pregnant women in the household, the geographical coordinates of the households/infrastructures. Administrative boundary point and polygons geographical shapefiles were provided by IITA [14].

To ensure that data from each household was adequately documented and tracked, each household was assigned a unique identification number pre-printed on each IRS card. Data collected on field and IRS card numbers were recorded on the questionnaires for each household by data collectors. The IRS card was given to a representative of the household as evidence of enumeration. The entries were checked and validated by field supervisors when the questionnaires were submitted.

Followed by data collection tools that captured GPS coordinates, household identification (IRS card number), village/town name/ward, name of head of household, number of individuals residing in each household, number of children less than five years of age in the household, number of pregnant women in the household, the geographical coordinates of the households/infrastructures and dataset overlaid with administrative boundary map layers.

The variables used during this study, can be described as follows:

Wards: a division below state or region of a town, used for administrative purposes.

LGA: a lower area below the state or region, administered by a Local Government Council, which consists of many wards and towns.

Household: Is a group of family or individual living under the same roof and eating from the pot of meal.

Compounds: it is a big residential area, consisting of several households living together cooking from several meal pots but has common storage play ground and kitchen.

Household identification (IRS card number): A unique ID written on buidling and also on the IRS card for follow up identification of household members.

Village/town: A village is a place of closed human settlement with a population ranging from a few hundred to a few thousand.

Head of household: Is the person within the household who is responsible for feeding all memberd of the household and takes the highest decision.

Children less than five years of age: Any child in the house, whose age is between 0 
and 59 months.

Pregnant women: Any woman in the household with a confirmed ANC attendance that she is an expecting mother or at the later stage of her trimester and can been seen with eyes that she is physically pregenant.

\section{Data analysis}

Field data were validated, and quality checks were done to ensure that all data included in the spatial and demographic analysis represent unique household in Doma and Nassarawa Eggon LGAs true representation of the LGAs.

Tables of summary statistics of demographic indices captured in the GR were then obtained from initial data analysis performed using Microsoft Excel office package, and further confirmatory analysis was performed using Statistical Packages for Social Science-(SPSS) 17 version.

The additional Spatial analysis was done after checking to ensure that the accuracy of dimensions set up in the configured GPS units was adhered to. ArcMap 10 version [15] was used to verify proxy locations of household points as they were overlaid with community layers and geo-referenced wards, followed by advanced geospatial statistical test, we then set null hypothesis $\left(\mathrm{H}_{0}\right)$, to confirm if the location of household per ward with respect to number of pregnant women and children is as important as any other, towards the elimination of mosquitoes from every communities.

\section{Results}

Key findings from the GR were synthesized and reported as follows;

Table 1 presents the summary of data collected during the GR operation in Doma and Nassarawa Eggon LGAs. A total of 49,500 unique households were therefore included in the GR from 424 towns/villages from both LGAs.

Results reveal that there were 79,339 children who were less than five years of age in the two LGAs. This makes about $21 \%$ of total population of the areas covered by the GR. A total of 13,526 pregnant women were enumerated.

Table 2 presents household demographic summaries for both LGAs and indicates that Doma and Nassarawa Eggon LGAs have an average of 8.52 and 7.22 persons per household in both LGAs respectively. The estimates of household size by children and women in the two LGAs are also presented in Table 2.

Table 1. Overall summary of GC for Doma and Nassarawa Eggon LGAs.

\begin{tabular}{ccc}
\hline Indicator & Doma & Nassarawa Eggon \\
\hline Number of Wards & 10 & 14 \\
Number of towns/villages & 115 & 309 \\
Number of households & 19,928 & 29,572 \\
Overall households & 169,794 & 213,507 \\
Children $<5$ years of age & 36,363 & 42,976 \\
Number pregnant women & 5578 & 7948 \\
\hline
\end{tabular}


The population of people recorded in the LGA was 169,794 and their distribution per ward is presented in Figure 3, reflecting that the population of people in the LGA were more concentrated in Galadima ward, with more pregnant women living there, while the lowest population density can be found in Doka ward. The locations of Primary Health Care (PHC) centers and the spatial distributions of pregnant women in the LGA are also shown in the same figure.

Figure 4 shows the distribution of household per ward, while Figure 5 presents the population distribution of people per ward in Nassarawa Eggon ward. Spatial analysis suggests that the highest population density was recorded in Doka, Madauchi, Madaki and Sabongari.

Figure 6 presents the topographic nature of the surveyed area, the map of Nassarawa Eggon showing spread of water bodies, major roads, water areas and elevations in the LGA.

Table 2. Household (HH) population summary in Doma and Nassarawa Eggon LGAs.

\begin{tabular}{ccc}
\hline Indicator & Doma & Nassarawa Eggon \\
\hline Average number of HH size & 8.52 & 7.22 \\
Average number of children $<5$ yrs/per $100 \mathrm{HH}$ & 183 & 118 \\
Average number of pregnant women/per $100 \mathrm{HH}$ & 28 & 22 \\
\hline
\end{tabular}

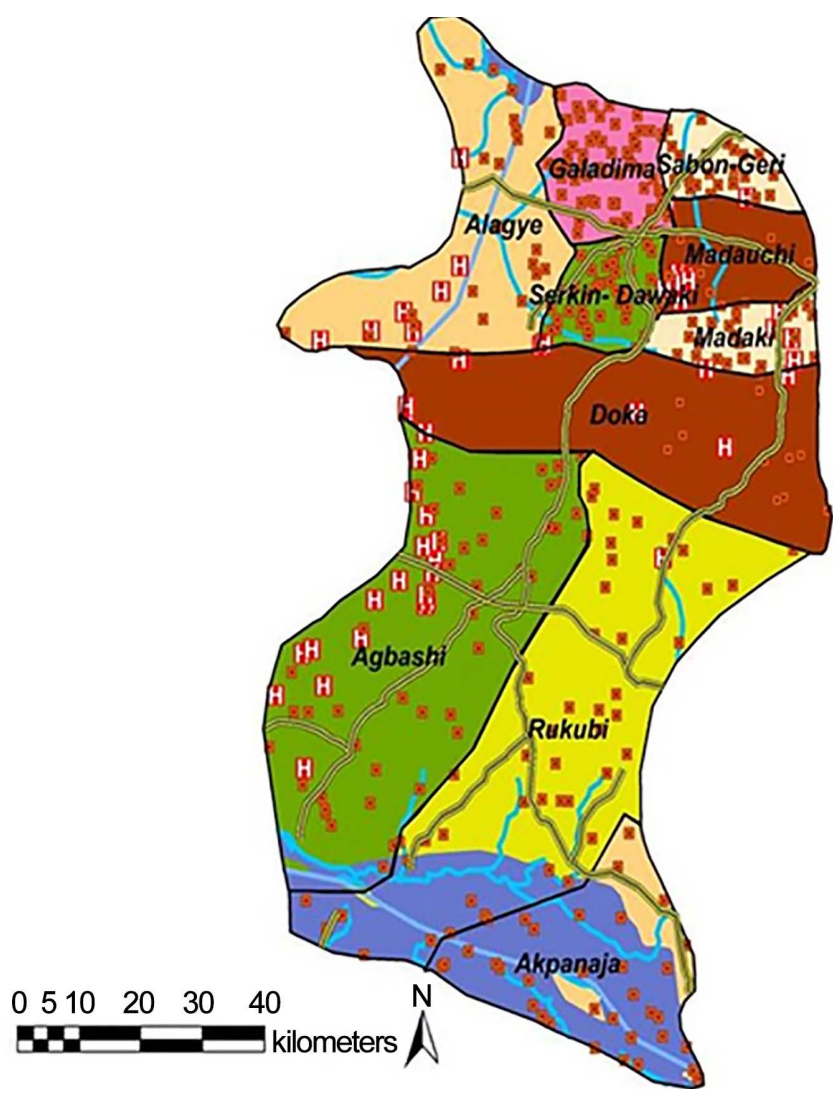

\section{Legend}

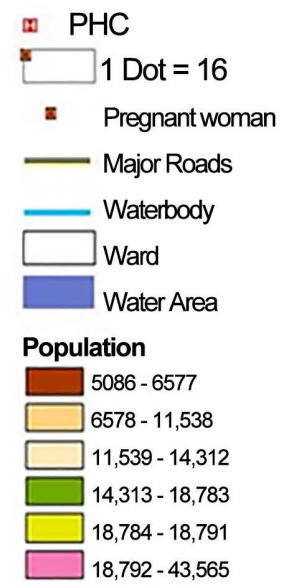

Figure 3. Map of Doma LGA showing the population distributions per ward. 


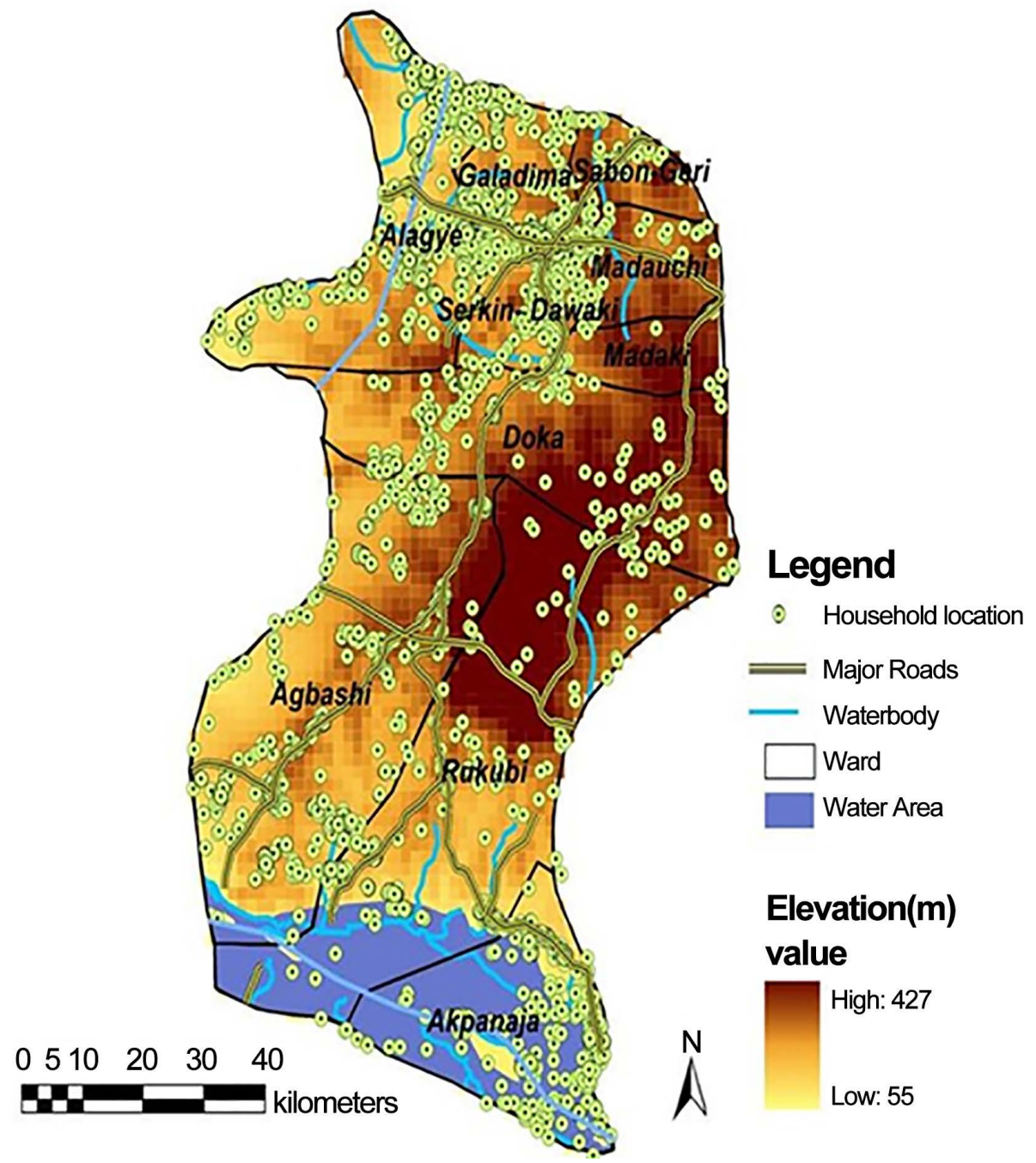

Figure 4. Topographic map of Doma LGA.

The pattern of test statistic generated by comparing for level of household concentration that has more pregnant women and children, who seems to be more vulnerable to malaria infections. The accessibility score index indicated highly statistically significant $\mathrm{p}$-level at $(\mathrm{p}<0.05)$ and positive $\mathrm{z}$-value as shown in Figure 7 . and thus we must reject the null hypothesis set above $\left(\mathrm{H}_{0}\right)$, confirming that location of household per ward with respect to high percentage of pregnant women and children is important towards the elimination of mosquitoes from every communities using the Indoor Residus Spray methods.

\section{Discussion}

The use of modern GR approach has proven to be accurate, efficient, cost effective and less cumbersome than the traditional approach in the collection and geo-positioning of household data [16]. This GR operation was able to capture geo-locations of all HHs in the focus LGAs and well as the population density of the target population. The data 


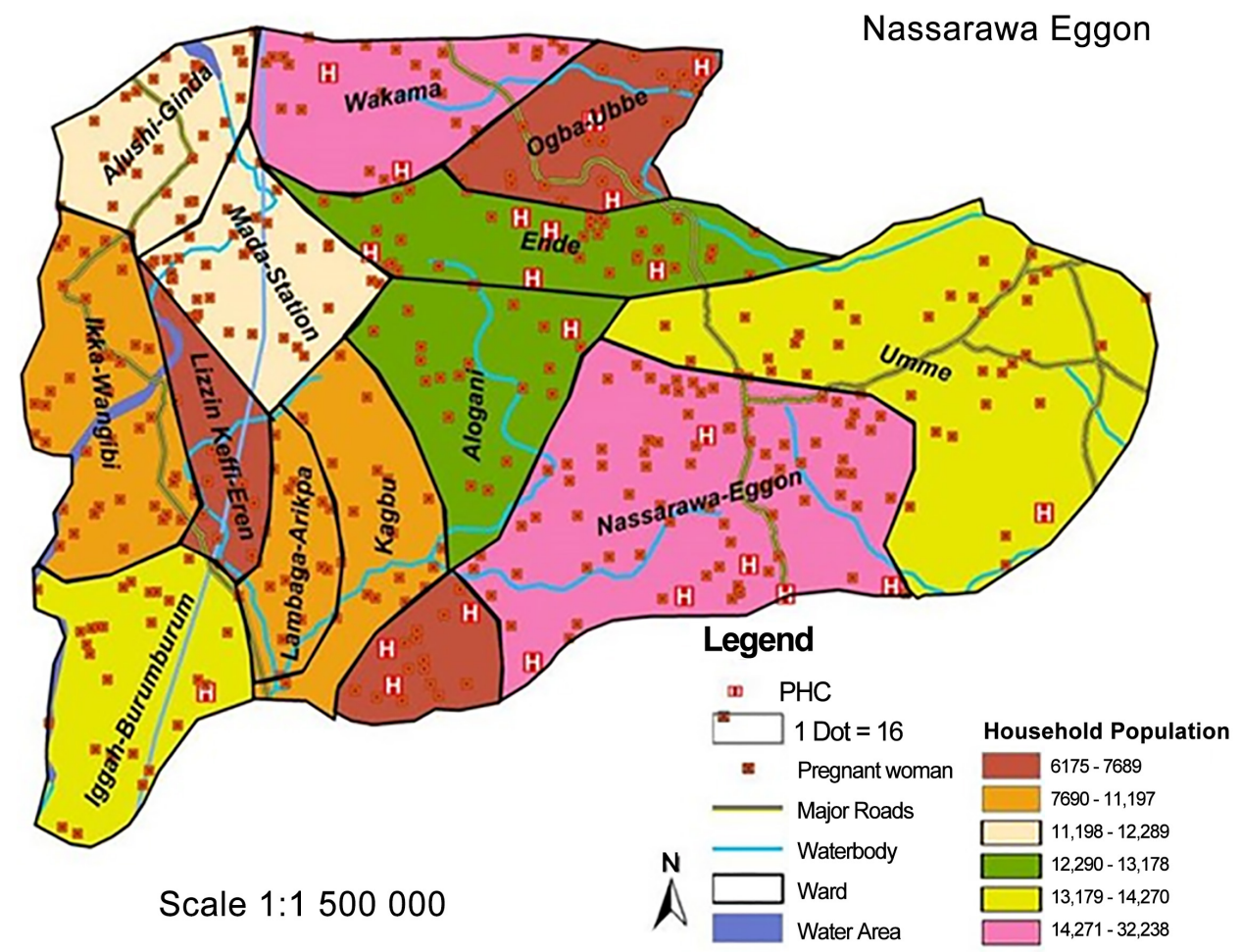

Figure 5. Map of Nassarawa Eggon showing the population distributions per ward.

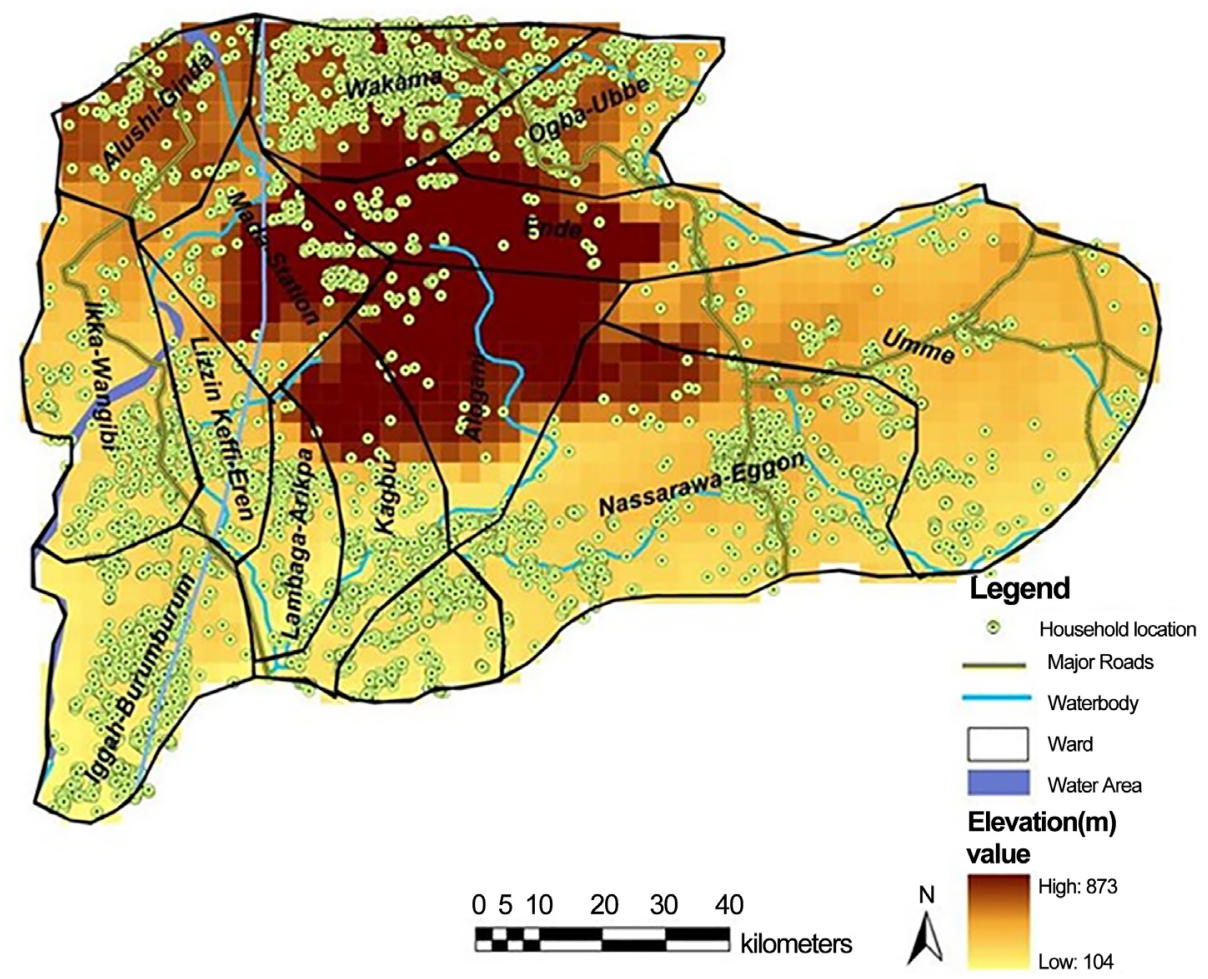

Figure 6. Topographic map of Nassarawa Eggon LGA. 


\section{Spatial Autocorrelation Report}

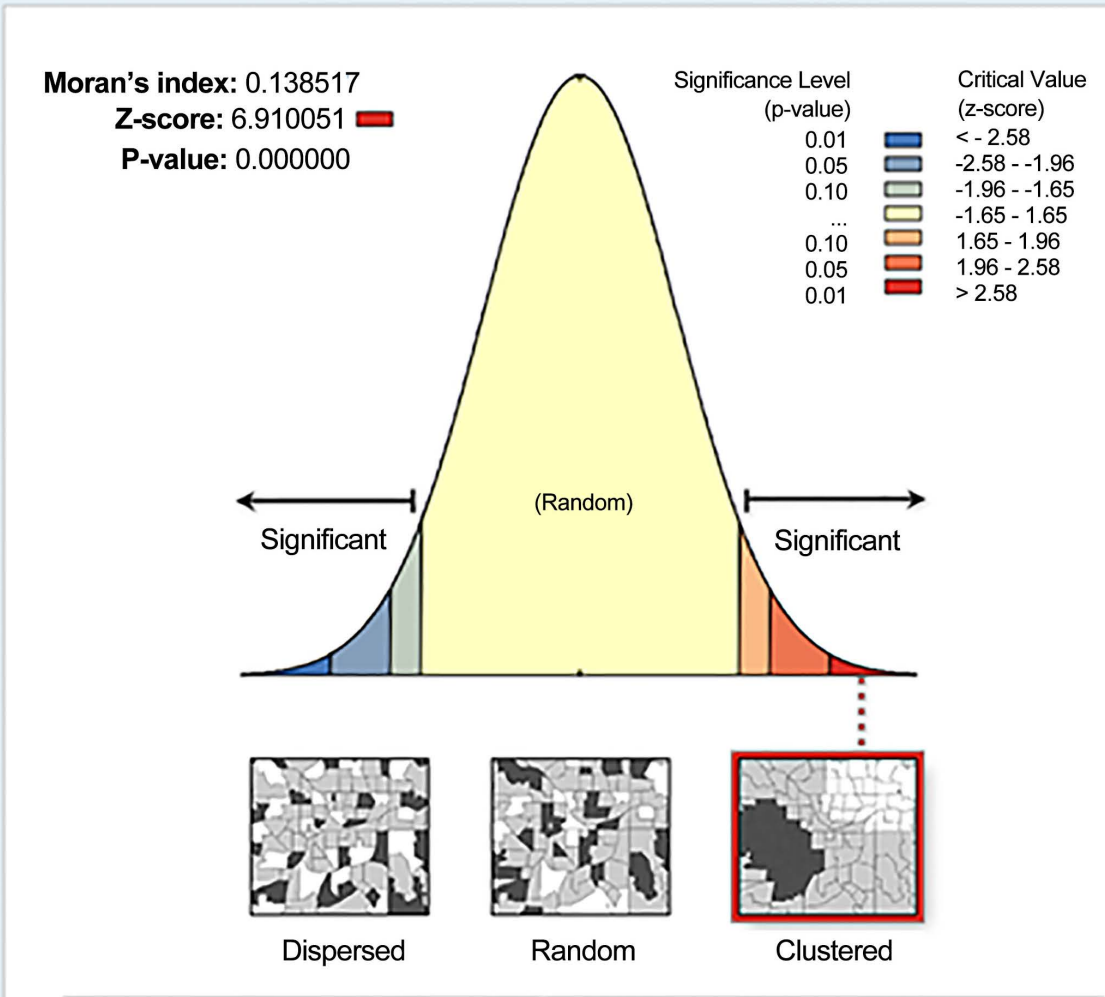

Given the z-score of 6.91005116674 , there is a less than $1 \%$ likelihood that this clustered pattern could be the result of random chance.

\section{Global Moran's I Summary}

Figure 7. Spatial autocorrelation results among ward households in both LGAs.

presented was helpful for planning the IRS campaign in the 2 LGAs. Such planning helped in the prudent use, management and deployment of human and material resources for the spray operation. However, due to the large number of households earmarked for enumeration in this GR exercise, standardized tools were used along with Garmin e-trex GPS handheld instruments to collect household data in the designated areas. This approach removed the constraint of deploring expensive and not readily available PDAs on field. With the recent development of modern technology, real time data collection with mobile devices with apps could prove even more effective in implementing a GR of this scale. Several African countries which did not use GR or applied the use of Geospatial tool appropriately had set back. Like in the case of Malawi, the IRS activities was characterized by substantial inherent logistical and technical challenges culminating into missed targets [17], this set back was avoided in our study here in Nigeria.

The strength of the evidence presented in this paper is based on the rigorous strategies employed to improve quality of data obtained from the GR exercise however, this could be achieved with the collection of GIS coordinates and HH information with the 
use of electronic data collection methods.

\section{Conclusions}

This exercise is a positive step in providing specific information to help with the implementation of IRS program and strategic surveillance monitoring of the selected areas. The data gathered during the GR provided the foundation for an updateable database for any future survey on IRS spray activities in Doma and Nassarawa Eggon LGAs.

The GR study gave a clear and precise standard approach of spatially defining and enumerating selected communities using a geo-spatial survey technology. The exercise and data collected were then used by the State NMCP and AIRS Project for vector control in these communities, better informed insecticides spray strategic plan, location of storage facilities and where more mosquito nets should be distributed.

The estimation of the distances between various locations was also helpful for effective local planning and logistics. The maps which were produced served the purpose, of providing spatial views of the household locations geographically in relation to other ecological factors and infrastructures in the LGAs.

The recommendation is that the Nigerian government and Development Partners should build on the strategy already put in place by the President's Malaria Initiative's Africa Indoor Residual Spraying Project (AIRS) through the National and State Malaria Control Program offices to use the outcome of this study to guide the reduction in malaria infection cases reported in every community. While other area of the country should see this as best practice and take a que from it [4].

\section{Acknowledgements}

We acknowledge the support and encouragement of the Africa Indoors Residual Spray (AIRS) Project team in Nassarawa State, Nigeria and United States Agency for International Development (USADI) AFRICA IRS (AIRS) which was funded by the US Agency for International Development (USAID) under contract No. GHNI00090001300. We also acknowledge the interest and participation of the National and State Malaria Program (NMCP) in Nigeria. http://www.africairs.net/where-we-work/nigeria.

\section{References}

[1] WHO (1999) World Health Organization Malaria RBM. http://www.who.int/whr/1999/en/whr99 ch4 en.pdf

[2] Hay, S.I., Guerra, C.A., Gething, P.W., Patil, A.P., Tatem, A.J., Noor, A.M., Kabaria, C.W., Manh, B.H., Elyazar, I.R., Brooker, S., Smith, D.L., Moyeed, R.A. and Snow, R.W. (2009) A World Malaria Map: Plasmodium Falciparum Endemicity in 2007. PLOS Medicine, 6, 0286-0302. https://doi.org/10.1371/annotation/a7ab5bb8-c3bb-4f01-aa34-65cc53af065d

[3] Tanner, M. and de Savigny, D. (2008) Malaria Eradication Back on the Table. Bulletin of the World Health Organization, 86, 82. http://doi.org/10.2471/BLT.07.050633

[4] ABT Associates Inc. (2014) USAID-Africa Indoor Residual Spraying, Initiatives. Bethseda publishing, Maryland.

[5] World Health Organization (1965) Geographical Reconnaissance for Malaria Eradication 
Programme. Geneva.

[6] Huang, H. (1980) Field Manual for Geographical Reconnaissance and Spraying Operations. Malaria Control Programme, Department of Public Health, Papua New Guinea.

[7] Nigeria News Portal (2016) Historical Development of Nassarawa State Came into Existence.

[8] Government of Zambia (2009) General Guidelines for Zambia's Indoor Residual Spraying. GOZ Press, Lusaka.

[9] National Population Commission (2006) Census Population Data.

[10] Yadav, K., Nath, M.J., Talukdar, P.K., Saikia, P.K., Baruah, I. and Singh, L. (2012) Malaria Risk Areas of Udalguri District of Assam, India: A GIS-Based Study. International Journal of Geographical Information Science, 26, 123-131. https://doi.org/10.1080/13658816.2011.576678

[11] Kelly, G.C., Hii, J., Batarii, W., Donald, W., Hale, E., Nausien, J., Pontifex, S., Vallely, A., Tanner, M. and Clements, A. (2010) Modern Geographical Reconnaissance of Target Populations in Malaria Elimination Zones. Malaria Journal, 9, 78-89.

[12] Gerald, C. (2013) A Spatial Decision Support System for Malaria Elimination. Ph.D Dissertation, Population Health Institution, The University of Queensland, Brisbane.

[13] Kelly, G.C., et al. (2010) Modern Geographical Reconnaissance of Target Populations in Malaria Elimination Zones. Malaria Journal, 9, 289.

http://www.malariajournal.com/content/9/1/289

https://doi.org/10.1186/1475-2875-9-289

[14] International Institute of Tropical Agriculture, Geospatial Lab (2012) Landcover Raster and Vector Shapefiles. Ibadan.

[15] Environmental Systems Research Institute-ESRI (2011) ArcGIS Desktop Release 10. Redlands.

[16] Shirima, K., et al. (2015) The Use of Personal Digital Assistants for Data Entry at the Point of Collection in a Large Household Survey in Southern Tanzania. Emerging Themes in Epidemiology, 4, 5 .

[17] Chanda, E., et al. (2015) Preventing Malaria Transmission by Indoor Residual Spraying in Malawi: Grappling with the Challenge of Uncertain Sustainability. Malaria Journal, 14, 254.

\section{Scientific Research Publishing}

\section{Submit or recommend next manuscript to SCIRP and we will provide best service for you:}

Accepting pre-submission inquiries through Email, Facebook, LinkedIn, Twitter, etc.

A wide selection of journals (inclusive of 9 subjects, more than 200 journals)

Providing 24-hour high-quality service

User-friendly online submission system

Fair and swift peer-review system

Efficient typesetting and proofreading procedure

Display of the result of downloads and visits, as well as the number of cited articles

Maximum dissemination of your research work

Submit your manuscript at: http://papersubmission.scirp.org/

Or contact jgis@scirp.org 